\title{
Lurasidone in the Treatment of Bipolar Depression: Systematic Review of Systematic Reviews
}

\author{
Michele Fornaro, ${ }^{1,2}$ Domenico De Berardis, ${ }^{3}$ Giampaolo Perna, ${ }^{4,5,6}$ Marco Solmi, ${ }^{7,8}$ \\ Nicola Veronese, ${ }^{8,9}$ Laura Orsolini, ${ }^{10}$ Elisabetta Filomena Buonaguro, ${ }^{2}$ Felice Iasevoli, ${ }^{1}$ \\ Cristiano André Köhler, ${ }^{11}$ André Ferrer Carvalho, ${ }^{11}$ and Andrea de Bartolomeis ${ }^{1}$ \\ ${ }^{1}$ Laboratory of Molecular and Translational Psychiatry, Department of Neuroscience, School of Medicine, \\ University "Federico II", Naples, Italy \\ ${ }^{2}$ New York State Psychiatric Institute, Columbia University, New York, NY, USA \\ ${ }^{3}$ National Health Service, Department of Mental Health, Psychiatric Service of Diagnosis and Treatment, \\ Hospital "G. Mazzini", ASL 4, Teramo, Italy \\ ${ }^{4}$ Department of Clinical Neurosciences, Hermanas Hospitalarias, Villa San Benedetto Menni Hospital, FoRiPsi, \\ Albese con Cassano, 22032 Como, Italy \\ ${ }^{5}$ Department of Psychiatry and Neuropsychology, Maastricht University, 6200 MD Maastricht, Netherlands \\ ${ }^{6}$ Department of Psychiatry and Behavioral Sciences, Leonard Miller School of Medicine, Miami University, Miami, FL 33136, USA \\ ${ }^{7}$ Department of Neurosciences, University of Padua, Padua, Italy \\ ${ }^{8}$ Institute for Clinical Research and Education in Medicine (IREM), Padua, Italy \\ ${ }^{9}$ Department of Medicine (DIMED), University of Padua, Padua, Italy \\ ${ }^{10}$ School of Life and Medical Sciences, University of Hertfordshire, Hatfield, Herts, UK \\ ${ }^{11}$ Translational Psychiatry Research Group and Department of Clinical Medicine, Faculty of Medicine, \\ Federal University of Ceará, Fortaleza, CE, Brazil
}

Correspondence should be addressed to Michele Fornaro; dott.fornaro@gmail.com

Received 31 October 2016; Revised 1 February 2017; Accepted 21 February 2017; Published 9 May 2017

Academic Editor: Chi-Un Pae

Copyright (C) 2017 Michele Fornaro et al. This is an open access article distributed under the Creative Commons Attribution License, which permits unrestricted use, distribution, and reproduction in any medium, provided the original work is properly cited.

Introduction. A burgeoning number of systematic reviews considering lurasidone in the treatment of bipolar depression have occurred since its Food and Drug Administration extended approval in 2013. While a paucity of available quantitative evidence still precludes preliminary meta-analysis on the matter, the present quality assessment of systematic review of systematic reviews, nonetheless, aims at highlighting current essential information on the topic. Methods. Both published and unpublished systematic reviews about lurasidone mono- or adjunctive therapy in the treatment of bipolar depression were searched by two independent authors inquiring PubMed/Cochrane/Embase/Scopus from inception until October 2016. Results. Twelve included systematic reviews were of moderate-to-high quality and consistent in covering the handful of RCTs available to date, suggesting the promising efficacy, safety, and tolerability profile of lurasidone. Concordance on the drug profile seems to be corroborated by a steadily increasing number of convergent qualitative reports on the matter. Limitations. Publication, sponsorship, language, citation, and measurement biases. Conclusions. Despite being preliminary in nature, this overview stipulates the effectiveness of lurasidone in the acute treatment of Type I bipolar depression overall. As outlined by most of the reviewed evidence, recommendations for future research should include further controlled trials of extended duration.

\section{Introduction}

Although the Diagnostic and Statistical Manual for Mental Disorders-Fourth Edition (DSM-IV) [1] poses mania as the hallmark of bipolar disorder (BD), depression is often the most enduring facet of the illness as emphasized by the Fifth edition of the Manual [2] requiring significant treatment efforts [3]. Yet, only a handful of randomized clinical trials 
(RCTs) exist about bipolar depression in comparison to major depressive disorder (MDD), which may be because unipolar "endogenous" or "melancholic" major depression episodes (MDEs) have long been considered equivalent to bipolar MDEs, from clinical, neurobiological, and treatmentmodality standpoints [4]. Regrettably, the only reservation was that antidepressants might switch to the manic pole; thus the enduring common clinical practice among clinicians was to seamlessly transpose the clinical data and wisdom from the treatment of unipolar to bipolar depression [5].

This later misconception has long been corroborated by anecdotal reports suggesting that most clinicians may still perceive medications as belonging to a class with regard to a specific therapeutic action rather than based on aimed "neuroscience-nomenclature" approach grounded on the pharmacological profile of the drug [6], both in the specialty and in general practice settings accessed by patients with BD [7]. Yet, therapeutic "class effect" in BD is an exception rather than rule [8].

The majority of patients with bipolar depression fail to respond adequately to pharmacotherapy [9], whereas the use of standard antidepressant medications, even when associated with established mood-stabilizers, poses major efficacy concerns beyond overall short- and long-term tolerability issues, especially for Type I BD (BD-I) and/or in the presence of associated mixed and/or atypical features, just to mention few $[10,11]$.

In contrast, evidence in support of the use of at least some of the second-generation antipsychotic (SGA) mono- or addon therapy either for MDD [12, 13] or bipolar depression [1418 ] is increasing over the time, though additional safe and effective Food and Drug Administration- (FDA-) approved SGAs for bipolar depression are solicited [19].

Currently, olanzapine-fluoxetine combination (OFC), quetiapine (either the standard or the extended release preparation), and lurasidone are the only FDA drugs granted (extended) approval for the (acute) treatment of bipolar depression in adults $[20,21]$.

Lurasidone received FDA approval for the treatment of schizophrenia in adults in October 2010 and was granted extended approval on June 2013 for the treatment of acute depression associated with BD-I in adults [22], either as monotherapy [23] or as adjunctive treatment to either lithium or valproate [24] flexible-dose regimen trials, further assessed in subsequent retrospective/prospective data analysis [25].

Potential safety (namely, the risk to the subject/patient, usually assessed in by laboratory testing [e.g., clinical chemistry and hematology], physical examination [vital signs], clinical adverse event[s], AEs, and other tests, e.g., the electrocardiogram), tolerability (namely, the degree to which overt AEs can be tolerated by the subject/patient), and effectiveness (usually, "effectiveness" trials [pragmatic trials] measure the degree of beneficial effect under "real world" clinical settings rather than the "efficacy" tested by "explanatory" trials aiming at determining whether an intervention produces the expected result under ideal circumstances) of adjunctive lurasidone across a broad range of treatment resistant $\mathrm{BD}$ outpatients otherwise excluded by routine clinical trials (e.g., those with mixed and/or rapid-cycling features; those taking additional psychiatric or nonpsychiatric medications; and/or older-age cases of $\mathrm{BD}$ ) have been preliminarily postulated [26-29] though critically appraised by independent authors [30].

While the overall effect size of OFC, quetiapine (regardless of release formulation), and lurasidone in mitigating depressive symptoms is similar, the later one showed a lower propensity for weight gain as well as overall metabolic neutrality in the bipolar population $[20,21]$.

Lurasidone, compared to previous FDA-approved SGAs for bipolar depression, yielded comparable benefits (all had single-digit number needed [NNT] for treatment versus placebo response or remission) and less risk of harm (doubledigit or greater numbers needed to harm [NNH] with lurasidone compared to single-digit NNHs for sedation with quetiapine and for $\geq 7 \%$ weight gain with olanzapinefluoxetine combination) and thus a substantially more favorable likelihood to be helped or harmed $[\mathrm{LHH}](>$ or $\gg 1)$ with lurasidone monotherapy and adjunctive therapy, compared to quetiapine and olanzapine-fluoxetine combination ( $\mathrm{LHH}$ $<$ or $\sim 1$ ) [31]. NNT, NNH, and LHH represent widely well-recognized indexes most clinicians are progressively becoming familiar with [32]. Nonetheless, the overall clinical validity and generalizability of these later indexes have been seldom questioned by some [33].

A burgeoning number of systematic reviews have nonetheless occurred since the pivotal RCTs leading to FDA extended approval of lurasidone, as the need for better efficacy/tolerability profile drugs for bipolar depression still represents a priority for the prescribing clinicians, policy-makers, and the suffering ones, indeed.

More recently, calls have been made for updated brief reviews to provide decision-makers with the essential evidence they need in a shorter time frame, but the possible limitations of such brief reviews, compared to full-systematic reviews, require further methodological research [34].

In recent years, however, decision-makers who were once overwhelmed by the number of individual studies have become faced by a plethora of reviews [35, 36]. This is compelling, especially when novel compounds of potential priority interest for the clinical practice like lurasidone, even in the treatment of $\mathrm{BD}$, may need to await for additional RCTs to allow reliable meta-analytic pooling $[37,38]$.

Therefore, while awaiting for additional primary research trials to allow reliable and large-scale quantitative extractions, varying approaches have been proposed [39] to promote quality assessment of systematic reviews of systematic reviews (or overviews) to be eventually accounted for subsequent umbrella reviews (broad coverage of systematic reviews and meta-analyses) [40]. Among others, several approaches including the Preferred Reporting Items for Systematic review and Meta-Analysis-Protocols, PRISMA-P [41] (formerly, PRISMA, QUOROM), or organizations devoted to the preparation of systematic reviews, including the National Institute of Health and Clinical Excellence (NICE) in the UK, the Evidence-based Practice Centre Program in the US, the Joanna Briggs Institute, and the International Campbell and Cochrane Collaborations arose [39]. It was not until 2009 that "A Measurement Tool to Assess Systematic Reviews" 
TABLE 1: Search strategy across alternative databases (queries run on October 14, 2016).

\begin{tabular}{|c|c|}
\hline Set & Medline (via PubMed) \\
\hline 1 & \#1 Lurasidone Hydrochloride [MeSH Major Topic] ${ }^{*}$ \\
\hline 2 & \#2 review[Publication Type] OR meta-analysis[Publication Type] \\
\hline 3 & Sets $1-2$ were combined with "OR" \\
\hline 4 & Bipolar disorder \\
\hline 5 & Depression \\
\hline 6 & Sets 1-5 were combined with “OR” \& “AND” \\
\hline \multirow[t]{2}{*}{$\begin{array}{l}\text { Most permissive (generic PubMed - no } \\
\text { MeSH headings) }\end{array}$} & ((Lurasidone) AND Bipolar) AND review[Publication Type] \\
\hline & Embase \\
\hline \multirow[t]{2}{*}{ Most permissive } & $\begin{array}{l}\# 1 \text { "lurasidone"/exp OR lurasidone AND "bipolar depression":ab,ti } \\
\text { AND review:it }\end{array}$ \\
\hline & Scopus \\
\hline \multirow[t]{2}{*}{ Most permissive } & $\begin{array}{c}\text { (TITLE-ABS-KEY (lurasidone) AND TITLE-ABS-KEY (bipolar } \\
\text { disorder)) AND DOCTYPE (re) }\end{array}$ \\
\hline & Cochrane Library \\
\hline Most permissive & $\begin{array}{l}\text { "Lurasidone in Title, Abstract, Keywords and 'bipolar disorder' in } \\
\text { Title, Abstract, Keywords and 'review' in Publication Type" }\end{array}$ \\
\hline
\end{tabular}

Note. Words written in italic were used as MeSH headings; the others were used as free text.

${ }^{*}$ Proposed entry terms, then accounted as free text integrations:

Hydrochloride, Lurasidone

Lurasidone $\mathrm{HCl}$

$\mathrm{HCl}$, Lurasidone

SM 13496

13496, SM

SM13496

SM-13496

SM-13,496

SM 13,496

SM13,496

Lurasidone

N-(2-(4-(1,2-benzisothiazol-3-yl)-1-piperazinylmethyl)-1-cyclohexylmethyl)-2,3 bicyclo(2.2.1)heptanedicarboximide Latuda.

(AMSTAR) was documented [42], proving to be a potentially reliable and valid assessment tool to specifically evaluate the methodological quality of systematic reviews [43].

Therefore, the aim of the present overview was to assess the methodological quality of systematic reviews assessing the evidence about lurasidone in the treatment of bipolar depression, with the ultimate goals of (i) ranking and prioritizing those reviews for which the methodology would allow reliable conclusions and recommendations for the future needs; (ii) critically pointing out which unmet needs and expectations have been highlighted by the clinician authors to be implemented by future lines of research about the pharmacological treatment of acute bipolar depression in adults with a special emphasis towards lurasidone, prompting for attention by policy and clinical decision-makers.

\section{Materials and Procedures}

Overall methods and procedures resemble those adopted by recent peer-review articles involving the use of AMSTAR methodology [42, 43], as applied to heterogeneous medical fields of research [45].
2.1. Search Strategy for the Identification of Systematic Reviews. A protocol was drafted before the implementation of the review (a copy is available from the authors). Searches were conducted of Medline (via PubMed), EMBASE and the Cochrane library (which includes the DARE database of abstracts of reviews on interventions), and Scopus, on October 14, 2016, and included a combination of free text and $\mathrm{MeSH}$ terms (please refer to Table 1). Despite the relatively recent introduction of lurasidone, indexes were searched from inception aiming at gathering as much information as possible on the topic. Searches were limited to "systematic reviews" or "review" type publication across varying sources. No language restrictions were imposed although only English language results were retained. This strategy was purportedly performed to get a better insight about any eventual language and regional publication differential trend on the topic. The title and abstract of each article were scanned (independently by two reviewers: MF and LO) and full-reprints of articles of potentially eligible reviews were obtained. Potentially eligible reviews were then screened, again independently by two reviewers, per the review selection criteria outlined below. All 
resulting references were further screened for identification of additional reviews.

2.2. Review Selection Criteria. Only systematic reviews were included. Case reports, controlled RCT (which were not part of a review), were excluded. Those narrative reviews indexed by major databases as "systematic" were nonetheless identified and then anyway screened for eventual inclusion and overall assessment. Both systematic reviews of RCTs and observational studies were eligible for inclusion. To be considered for inclusion, the review had to include evidence about the use of lurasidone (any dose) for bipolar disorder (any mood polarity), either for the acute or for the maintenance mono- or adjunctive treatment therapy. Systematic reviews covering drugs other than lurasidone or any additional non-BD prescription of lurasidone were likewise included in the present overview. Populations at interest were therefore "BD patients exposed to lurasidone."

2.3. Preliminary Data Abstraction. For each review meeting the inclusion criteria data were abstracted independently by two reviewers (MF and DDB). All data was compared and identified anomalies rectified by mutual agreement. Data were obtained exclusively from the systematic reviews, while additional manual screening was planned to enrich the search strategy. The primary study reports were likewise reviewed before assessment of systematic review reporting on the matter. Data abstracted from each systematic review included (i) authors and date of publication; country of origin (leading author most current affiliation); major biases, including sponsorship bias. In case of reviews covering multiple RCT studies, these later ones were punctually referenced in Table 2 (please see the text for results).

2.4. Assessment of Data Quality. The methodological quality and risk of bias of the systematic reviews at interest were performed using the AMSTAR items [42, 43] by two independent reviewers (MF and DDB). Risk of bias of primary studies was not assessed where this was covered by the corresponding systematic reviews. However, we did not record whether and how the reviews had assessed the quality of the primary studies and which method had been used (for example the Cochrane risk of bias tool) [54]. Briefly, the AMSTAR is a tool aiming at addressing relevant domains (as applicable): establishing the research question and inclusion criteria before the conduct of the review, data extraction by at least two independent data extractors, comprehensive literature review with searching of at least two databases, key word identification, expert consultation and limits as necessary, detailed list of included/excluded studies and consideration of quality assessments in analysis and conclusions, appropriate assessment of homogeneity, assessment of publication bias, and a statement of any conflict of interest. Therefore, (i) the extent of searching undertaken; (ii) description of review selection and inclusion criteria; (iii) assessment of publication bias; (iv) assessment of heterogeneity; and (v) comparability of included reviews are emphasized by the AMSTAR method [39]. The AMSTAR checklist items are presented in the form of questions, with possible responses of "yes" (item/question fully addressed), "no" (item/question not addressed), "cannot answer" (not enough information to answer the question), and "not applicable," https://amstar.ca/Amstar_Checklist.php; the actual eleven domains rated by the AMSTAR and its psychometric features have been further detailed elsewhere [43].

The revised assessment of multiple systematic reviews (RAMSTAR) based on appendix 1 included in the open-access work by Kung et al. [44] was nonetheless integrated [55] to the standard AMSTAR to generate quantitative scores of qualitative evidence [44] since use of the original AMSTAR checklist alone would have posed subjectivity concerns and possibly reduced the reliability and replicability of assessments [56]. Specifically, stating the discrepancy existing about standardized scoring of the original AMSTAR domains [55-57], grading of the R-AMSTAR could vary across different authors and research themes [55]; we integrated two alternative scores methods in the assessment of each systematic review: (a) each of the individual eleven domains of the original instrument ranged between 1 and 4 (maximum); thus the R-AMSTAR total scores ranged between 11 (minimum) and 44 (maximum). Scoring for each domain could be determined based on the number of satisfied criteria varying across different domains rather than nonstandardized cut-off scores [44]; (b) based on the later scores values, a percentile ranking is obtained, for each individual score, which is then translatable into a letter grade based on the extent of PICO/PIPO research questions (population, intervention, comparison, prediction, and outcome) answered, with the following letters: A (best)-E (worst) range (variable across varying questions). Details about the domains and proposed scoring of the R-AMSTAR available in the public domain based on the appendix 1 are included in the work by Kung and colleagues $[44,55]$.

\subsection{Exclusion of Duplicate Primary Studies (Document in} Systematic Reviews). Both auto- and hand-searches for "type I" ("duplicates among/across different databases") and "type II" ("duplicate publications in different Journals/issues") [58] were performed based on Thompson Endnote $X 7^{\circledR}$ for Microsoft Windows ${ }^{\circledR}$.

Reviews were then screened to exclude systematic reviews with duplicate primary studies unless they reported on different outcomes or provided alternative critical account of the evidence.

2.6. Outcomes. Principal outcomes related to the impressions and recommendations about efficacy and tolerability made by the authors given a systematic review at review beyond the raw data come from the covered original RCTs. Specifically, overall conclusions drawn by the authors and unmet needs to be addressed by future studies were included providing a concise narrative synthesis based on each systematic review included in the present overview. Conversely, specific outcomes of treatment interventions reported by the original RCTs covered across varying reviews were not accounted herein. On the other side, it is worth mentioning that higher R-AMSTAR scores and letter grades (e.g., "A") would indicate more reliable and trustworthy conclusions. 


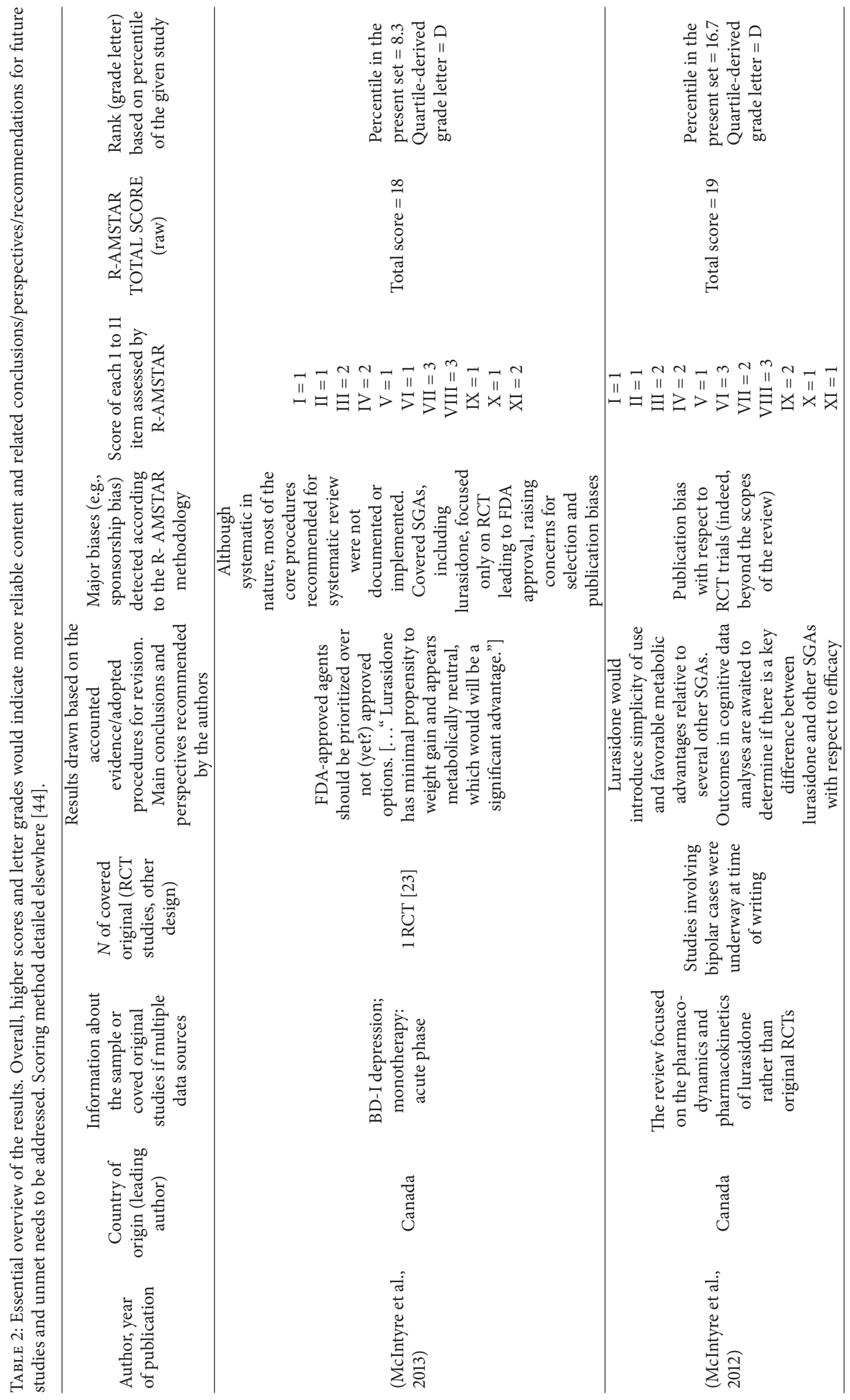




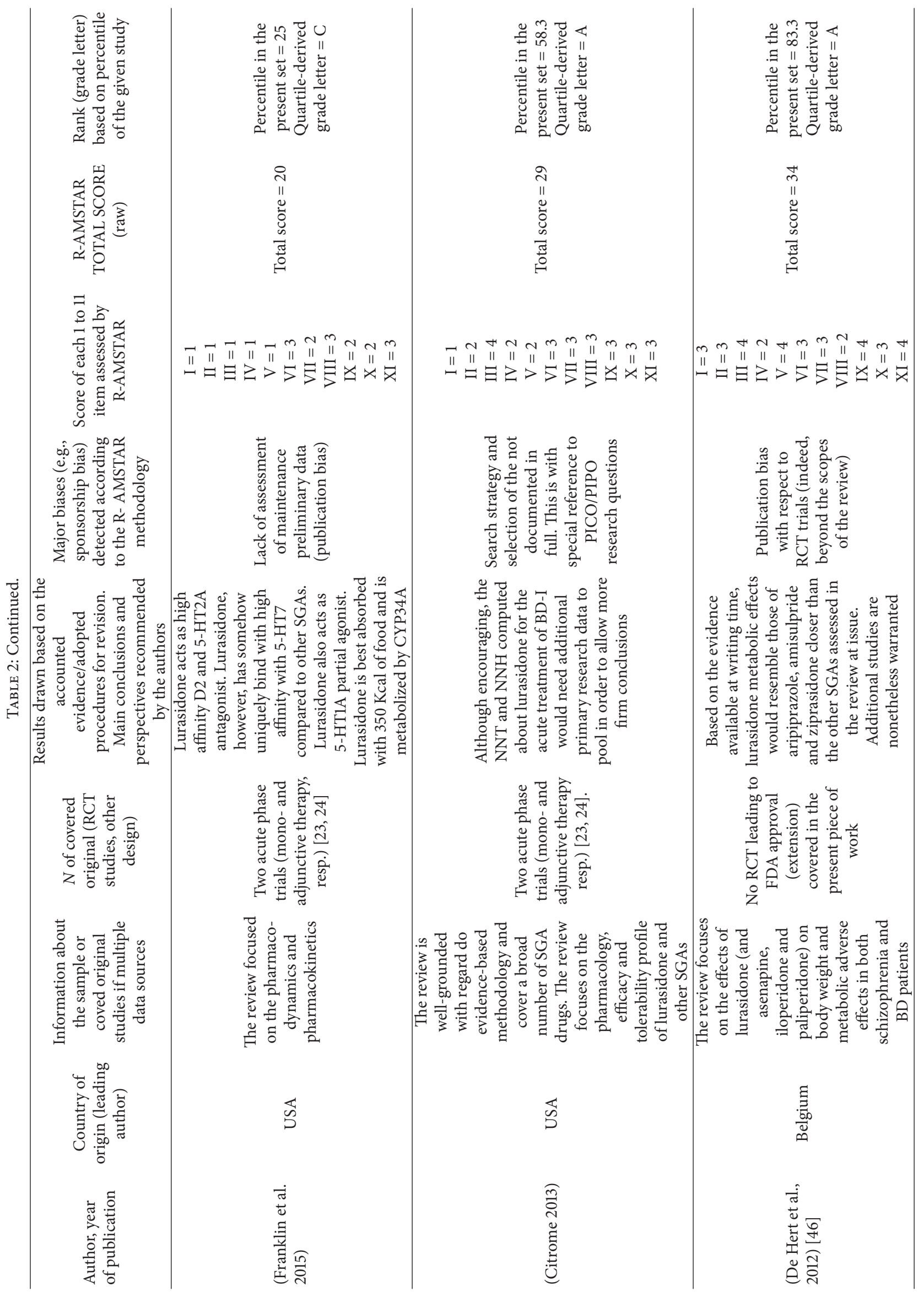




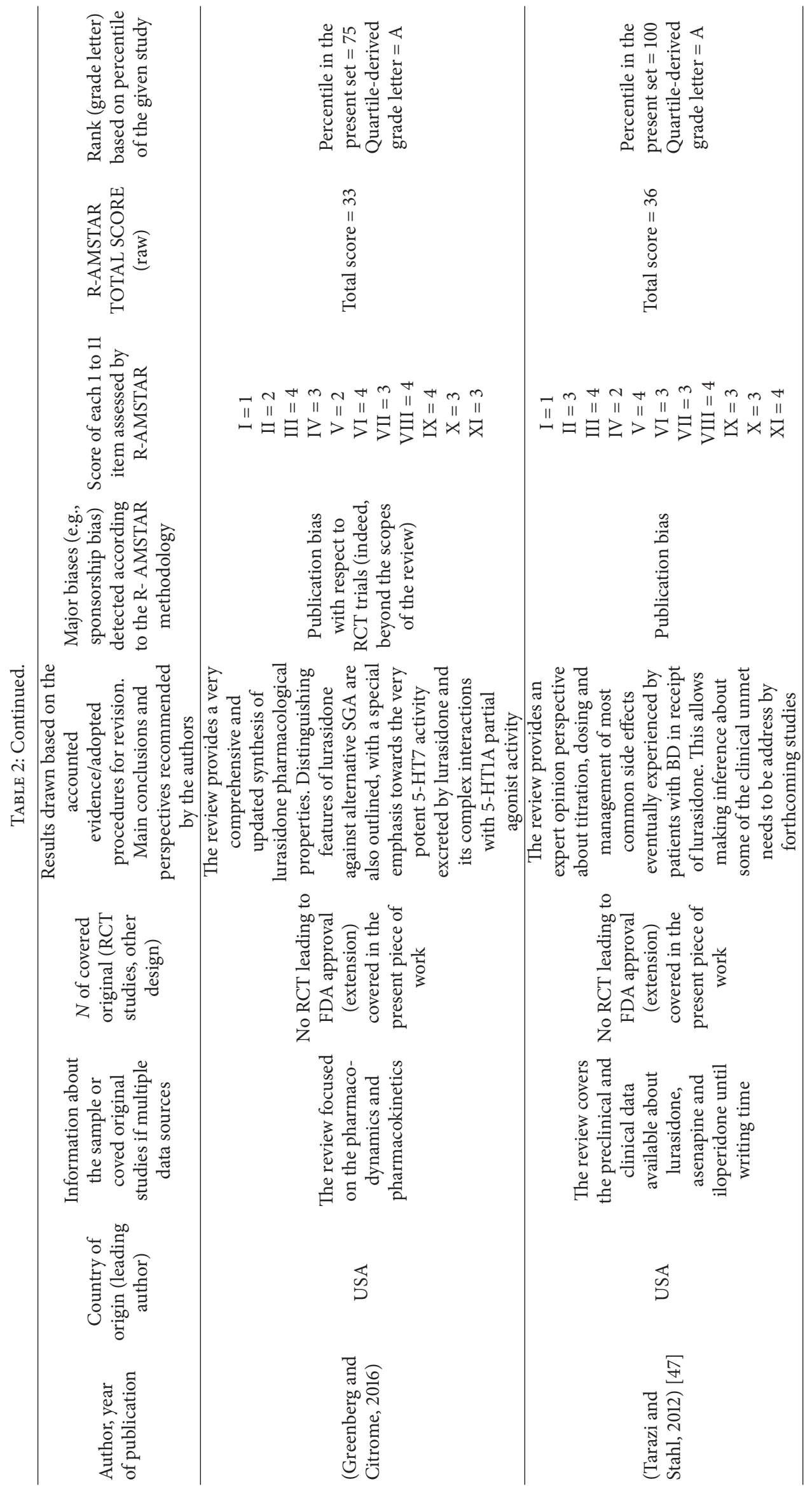




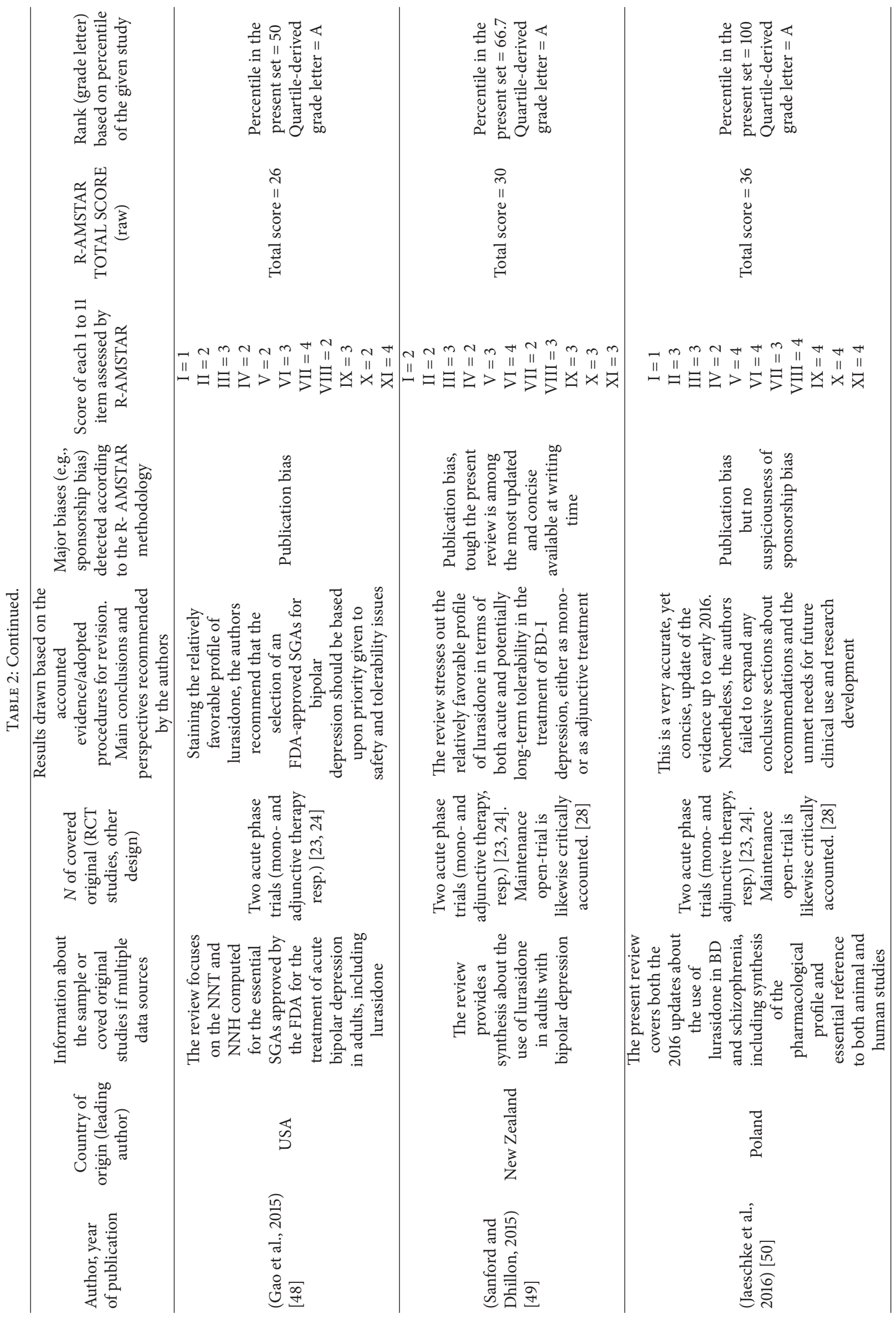




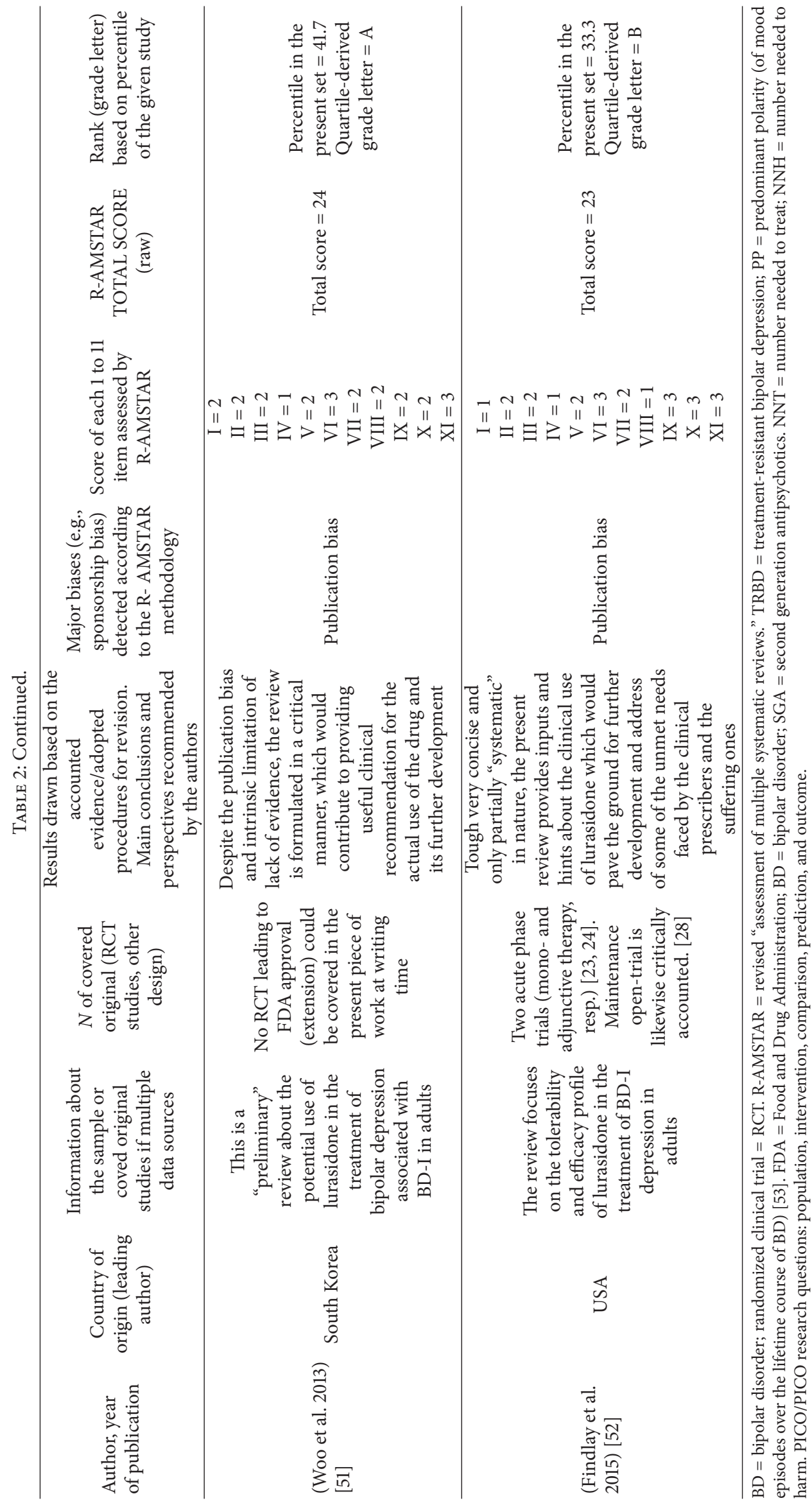


Adapted PRISMA-P 2015 Flow Diagram (Moher et al., 2015) for "overview" use

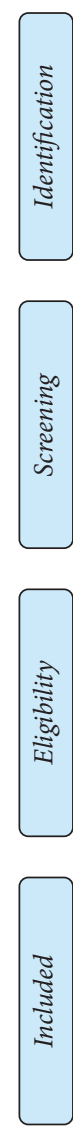

Potentially relevant reviews identified and screened for retrieval

( $n=149$, of which 41 in PubMed; 83 in Scopus; 0 in

Cochrane Library and 25 in Embase).

through other sources

(contact with the authors, cross-

references, $n=0$ )

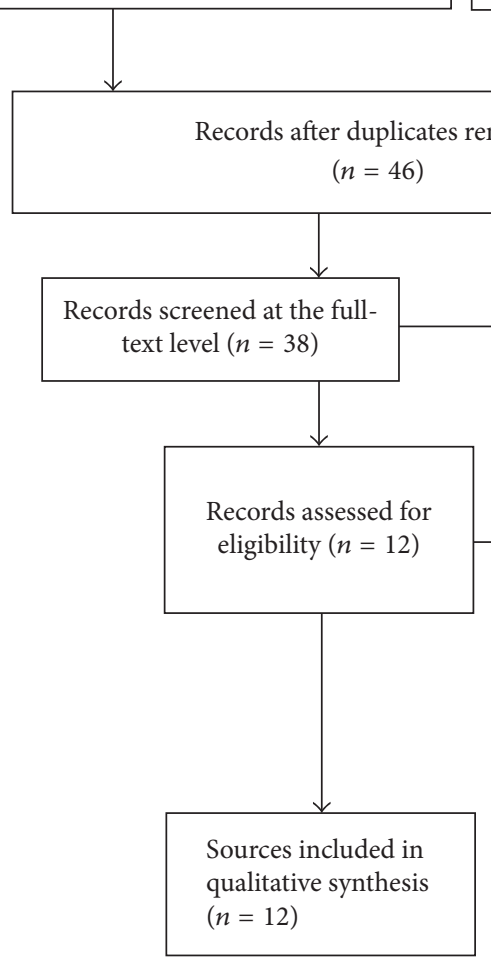

FIGURE 1: Flow chart of overview procedures.

\section{Results}

Stating the lack of quantitative data to abstract (please refer to Figure 1 for study flow chart) (e.g., treatment effect estimates), overall synthesis of results could be presented in a narrative fashion (as outlined in Table 2).

3.1. Overview of the Systematic Evidence. As depicted in Figure 2 and Table 3, most of the included "systematic" reviews fell in the upper tier of the quality range according to the percentile score (or related grade letter): R-AMSTAR total median score $=27.5$ (Interquartile-Range $[\mathrm{IQR}]=13$ ), whereas the range of raw R-AMSTAR scores was equal to $18-36$.

On average, only few original RCTs about lurasidone in the treatment of $\mathrm{BD}$ in adults could be "systematically reviewed" since 2013 (FDA extension of approval beyond schizophrenia). Moreover, both the pivotal acute mono[23] and adjunctive [24] therapy trials were sponsored ones, as is preliminary data about maintenance [29, 30]. Additional details about study design, outcomes and measures of the RCTs consistently covered across the systematically reviewed reviews or drug development with focus on bipolar depression [59] could therefore be retrieved in the respective references provided above.
TABLE 3

\begin{tabular}{lcc}
\hline R-AMSTAR total score & Frequency & Percentile \\
\hline 18.00 & 1 & 8.3 \\
19.00 & 1 & 16.7 \\
20.00 & 1 & 25.0 \\
23.00 & 1 & 33.3 \\
24.00 & 1 & 41.7 \\
26.00 & 1 & 50.0 \\
29.00 & 1 & 58.3 \\
30.00 & 1 & 66.7 \\
33.00 & 1 & 75.0 \\
34.00 & 1 & 83.3 \\
36.00 & 2 & 100.0 \\
\hline
\end{tabular}

Note. Percentiles $\leq 20.75$ would fall in the bottom 25 th quartile (grade letter "D"); percentile range 20.76-27.50 = lower 50th or letter C; percentile range 27.6-33.75 = upper quartile till 75 th, or letter B; percentiles $\geq 33.75$ would fall in the top quartile (up to 100th percentile), or letter grade "A."

3.2. Chemistry. Lurasidone hydrochloride (molecular formula $\mathrm{C}_{28} \mathrm{H}_{37} \mathrm{ClN}_{4} \mathrm{O}_{2} \mathrm{~S}$ ) is a benzisothiazolinone derivative. Its molecular weight is $529.14 \mathrm{~g} / \mathrm{mol}$. Figure 3 shows lurasidone chemical structure. Please access https://pubchem .ncbi.nlm.nih.gov/compound/Lurasidone_HCl\#section=Molecular-Formula for additional details. 


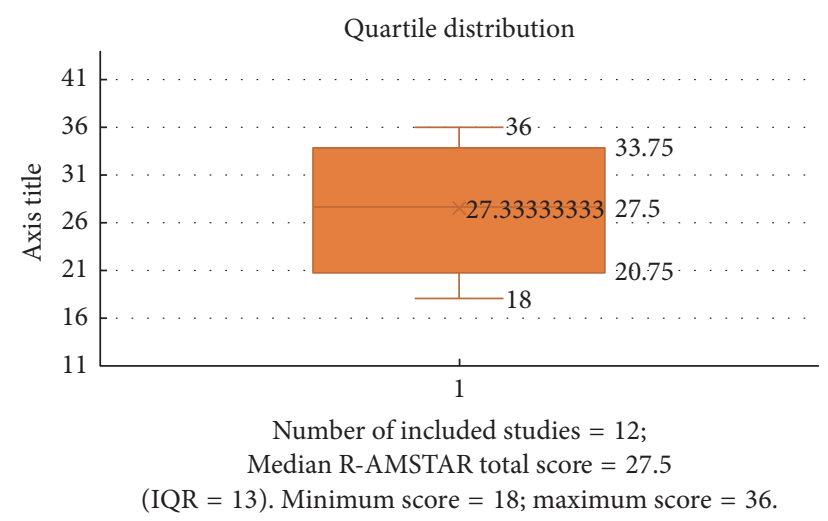

FIgURE 2: Companion box-plot and quartile distribution for Table 2: Conversion of raw R-AMSTAR total scores into percentile scores (see Table 3).

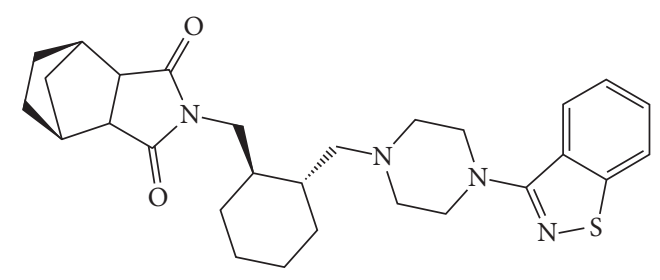

FIGURE 3: 2D conformer of lurasidone (compound: CID 11237860). Additional reference at https://pubchem.ncbi.nlm.nih.gov/compound/Lurasidone_HCl\#section=2D-Structure.

\subsection{Essential Pharmacokinetics and Pharmacodynamics Sig-} nature. Substantial consensus exists about the pharmacological signature of lurasidone hydrochloride across sources assessing either preclinical or clinical studies on the matter [60-64], as briefly synthesized below.

3.3.1. Essential Pharmacokinetics of Lurasidone. Lurasidone is metabolized by the liver via cytochrome (CYP) 3A4 [65] and it is best absorbed with $350 \mathrm{Kcal}$ of food as detailed elsewhere [66]. Although the requirement to take lurasidone with food is minimal inconvenience [67], the ability to take it just once a day is an advance over alternative medications or polypharmacy regimens [63].

According to the US package insert, rifampin, a potent CYP3A4-inducer, decreased lurasidone area under the curve fivefold [68]. There are no published studies of potent antiepileptic drugs CYP3A4 inducers that are expected to dramatically increase lurasidone metabolism, including those seldom prescribed to BD patients too [69]. Nonetheless, it is possible that in high doses, oxcarbazepine or topiramate may influence lurasidone levels [70].

When prescribed as oral monotherapy for depression associated with BD-I in adults, initial dose should be $20 \mathrm{mg} /$ day, with no titration needed and maximum dose being $120 \mathrm{mg} /$ day depending on patient response, tolerability, and pharmacokinetics issues (in contrast to usually higher dose range of $80-120 \mathrm{mg} /$ day often required for adult cases of schizophrenia, when used as monotherapy in the absence of major pharmacokinetic interactions) $[61,71,72]$.

3.3.2. Essential Pharmacodynamics of Lurasidone. Lurasidone is a full antagonist at dopamine (DA) D2 and serotonin (or 5-hydroxytryptophan [5-HT]) 2A (5-HT2A) receptors, with binding affinities $(\mathrm{Ki})$ of 0.47 nanomole $(\mathrm{nM})$ and $0.994 \mathrm{nM}$, respectively $[61,73]$. However, lurasidone also has high affinity for serotonin 5 -HT7 receptors $(0.495 \mathrm{nM}$; comparable to D2 and 5-HT2A receptors) and has affinity as partial agonist at 5-HT1A receptors with a Ki of $6.38 \mathrm{nM}$ [72]. This may be of potential interest because of preclinical findings of a possible procognitive effect mediated by action at the serotonin 5-HT7 receptor [60, 61]. Notably, 5-HT7 blockade has been postulated to boost 5-HT1A modulation by lurasidone antagonism elsewhere postulated as a reinforcement of 5-HT1A activity [74]. Lurasidone is also low- to moderate D3 antagonist [75].

Lurasidone preclinical profile was found predictive of antipsychotic, antimanic, antidepressant, and procognitive effects [61], as well as efficacy against negative symptoms of schizophrenia [63]. Moreover, its lack of affinity for some receptors (e.g., histamine $\mathrm{H1}$, acetylcholine $\mathrm{M1}$ ) would predict improved (metabolic and cognitive) tolerability with respect to alternative SGAs options approved by the FDA for BD in adults $[61,63]$. Favorable D2/5-HT2A balance would predict lower propensity for extrapyramidal symptoms [64].

According to the original model proposed by Fountoulakis et al. [76], the stronger predictors for antidepressant efficacy in bipolar depression would encompass norepinephrine alpha-1, dopamine (DA) D1, and histamine antagonism, followed by 5-HT2A, by muscarinic and dopaminergic D2 and D3 antagonism, and eventually by norepinephrine reuptake inhibition and 5-HT1A agonist effect [76].

Yet, it is worth noting that the model would therefore outline a complex interaction between the major neurotransmitter systems without a single target being either necessary or sufficient to elicit the antidepressant effect in bipolar depression [76].

While serotonin reuptake inhibition may not play per se a significant role in bipolar depression [77], it is worth noticing that norepinephrine activity seems to be of great of importance [61]. Thus, early bipolar antidepressant activity excreted by lurasidone has been correlated with disinhibitory norepinephrinergic effects of agonistic activity at 5-HT1A (which may play a core mechanism in bipolar depression [78] beyond major depressive disorder [79]) and antagonism at alpha-1 norepinephrine and serotonin 5-HT2A receptors, though the presence of norepinephrine reuptake inhibition (lurasidone is also weak alpha-2a (autoinhibitory, presynaptic) antagonist $(\mathrm{Ki}=10.8 \mathrm{nM})$ for lurasidone [64] $)$ is essential in order to sustain it [61], whereas dopaminergic activity overall may likewise play a major role [80].

Finally, while lurasidone pharmacodynamic signature would represent a good fit of the model proposed by Fountoulakis et al. (2012) [76], additional peculiar pharmacodynamics of lurasidone [61], including strong 5-HT7 (and D2) antagonism, otherwise suggestive of procognitive and mood-enhancing activity possibly via dopamine efflux 
too [81-83], and negligible or null 5-HT3 and 5-HT2C interactions, otherwise accounted as major potential players for antidepressant activity in BD [84-86], could not fit the model, possibly due to lack of additional evidence on the matter (publication bias) rather than actual negligence of their neurobiological value on the matter [61].

\subsection{Adverse Effects Consistently Documented across Varying} Systematic Reviews Based on Original Studies. An updated synthesis on major and/or most common AEs with lurasidone (even) in the treatment of $\mathrm{BD}$ is provided elsewhere [64]. Briefly, the most commonly reported AEs were nausea, akathisia, EPS, and sedation. Negligible effects were seen with respect to changes in fasting glucose, total cholesterol, low-density lipoprotein cholesterol, prolactin elevation, and triglycerides' levels, at least in contrast with alternative SGAs and/or higher average dose regimens used for schizophrenia patients [87]. No electrocardiogram abnormalities, not even significant increase in QT interval length, have been documented in comparison with placebo or active competitor(s) from the SGA class. Stating the lack of histamine H1 and muscarinic M1, as well as strong norepinephrine alpha-1 antagonist, activities, lurasidone has also lower propensity to induce somnolence compared to most of the available SGA alternatives [88]. On the contrary, akathisia and dystonia were important, relatively common, AEs. In addition, it is worth noting that while the FDA black box warning about the risk of death in elderly patients with dementia has been issued as a class black box warning, lurasidone database does not have studies involving subjects with dementia and has no reported deaths in clinical trials in this population. Nonetheless, we purposely avoided providing quantitative synthesis of AEs herein as evidence from RCTs studies involving adult cases of $\mathrm{BD}$ is tentative or otherwise hampered by strong publication bias (and selection bias of included samples), and cumulative reports derived by some systematic reviews merged data from schizophrenia cases controlled as well as noncontrolled reports, with this later cases known to be prone to higher neurological side effects and being usually exposed to higher dose of antipsychotic(s) on average [64].

\section{Discussion}

The average quality of the included systematic reviews ranged between moderate-to-high scoring, as the mode ("most common statistical presentation") was equal to grade letter = "A" (namely, for 8 out 12 included studies). Overall, concordance exists about the intriguing efficacy, safety, and tolerability profile of lurasidone even in the treatment of acute depressive episodes associated with BD-I, especially when indirectly compared with other FDA-approved SGAs to date.

This later issue has major implications for the policymakers, the clinicians, the patients, and their caregivers, especially considering that most $\mathrm{BD}$ patients require longlasting (virtually lifetime enduring) pharmacological treatments (ideally integrated by alternative treatment modalities), thus being particularly vulnerable to many of the common AEs documented with some of the SGA class compounds already released, especially from cognitive and cardiometabolic standpoints [89]. Thus, there is interest towards lurasidone as a safer and more tolerable, yet efficacious, alternative to current pharmacological armamentarium.

Nonetheless, it must be remarked that the R-AMSTAR grading system is relative to the set at review, which does not necessarily mean absolute high quality of reporting for a given review out of the set at overview. This further solicits additional primary research studies (namely, RCTs to fill the gap of publication bias and allow meta-analysis of the evidence), as well as the need for higher quality of reporting of the forthcoming reviews (especially regarding the details documenting research protocols procedures and the biases encountered in the assessment of primary research, namely, publication and sponsorship bias, to this end). On the other side, the trend of publication of reviews about lurasidone confirms the clinicians' interest about this compound, even in the treatment of BD, as depicted in Figure 4.

Specifically, despite growing body of literature detailing the efficacy and tolerability of lurasidone, a complementary body of literature documenting its efficacy for the treatment of $\mathrm{BD}-\mathrm{I}$ is comparatively less than the one concerning other SGAs, essentially due to the short time since initial approval (subsequently extended beyond the sole treatment of schizophrenia). This later issue may also concur the explanation why most of the "systematic" reviews on the matter essentially focused on the pharmacodynamics and/or pharmacokinetics of the drug rather than on RCT studies [90]. In this regard, it is also worth noticing that the upcoming clinical trials should ideally investigate the impact of current and/or lifetime mixed features as primary outcomes. Similarly, greater attention and stratification of the reported results by upcoming RCTs should focus on psychotic features and (emerging) suicidality, which would on turn demand for extended longitudinal follow-up, including flexible-dose regimen arms, to better investigate medication adherence to lurasidone across varying dosing patterns [91]. This is particularly true considering that $\mathrm{BD}$ and mood disorders in general should be better evaluated from an extended longitudinal perspective, as originally postulated by Emil Kraepelin for "manic-depressive illness" [17, 18].

4.1. Study Limitations. Sponsorship, publication biases, and shortage of grey literature on the matter may have limited the availability of negative result trials documented either by primary or secondary research reports. Though assessed for methodological quality, additional biases inherent to the original field trials (e.g., selection bias) may have hampered the generalizability of the overall conclusions drawn herein. Both the psychometric properties and scoring guidance of the adopted R-AMSTAR may still lack in terms of validity (measurement bias). In addition, most of the included studies were written in the English language (potential language bias). English-written papers are likely to be published more rapidly (time-lag bias) and cited more often (citation bias). This is compelling for novel compounds as the mentioned publication bias may represent an issue especially in the 


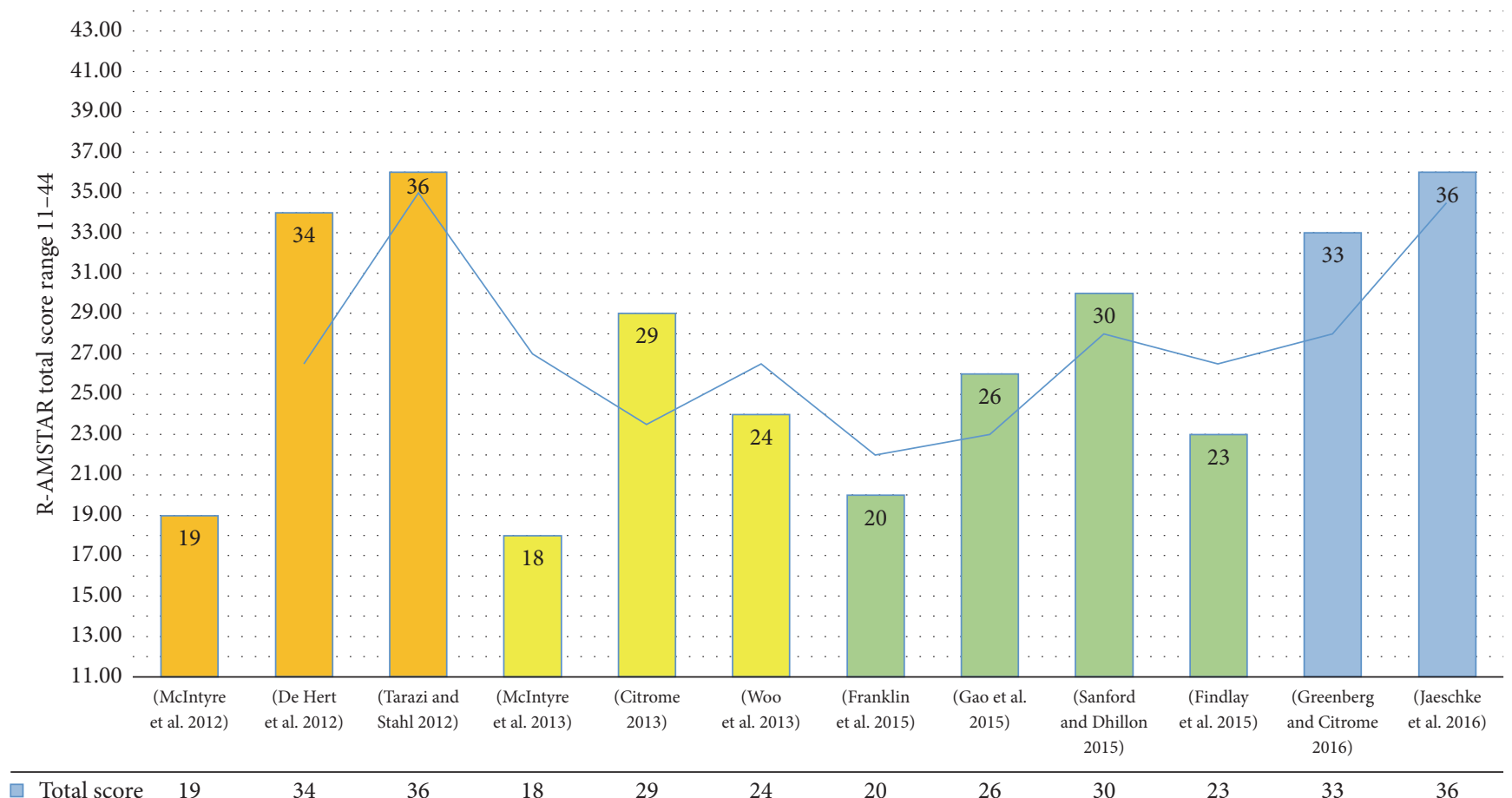

FIGURE 4: Number of studies and quality as assessed by the "Revised-A measurement tool to assess the methodological quality of systematic reviews" (R-AMSTAR) [44] total score for systematic reviews, per year. Note: 2016 records could be updated till late October.

absence of negative results reports and in the presence of sponsored RCTs only to date.

\subsection{Lurasidone in the Treatment of Bipolar Depression: Major} Clinical Implications and Recommendations for Future Clinical Studies to "Meet the Unmet Needs". The Program to Evaluate the Antidepressant Impact of Lurasidone (PREVAIL) planned in 2009 by lurasidone manufacturer with the goal to evaluate the efficacy and tolerability of lurasidone as both a monotherapy and as an adjunctive therapy in adult patients purportedly excluded psychotic cases of depression associated with BD-I [59]. While this later strategy was intended to ensure improvement of depressive ratings due to specific antidepressant efficacy of lurasidone rather than effect of the psychotic features (excluded per protocol), concerns regarding the chance of Berkson's bias for subsequent efficacy results are documented in the developed acute and open-phase extension trials which lead to FDA approval. Thus, future trials should ideally include representative samples of BD-I depression with concurrent psychotic features too [92] and stratify results accordingly, as alternative post hoc analyses (e.g., $[59,67,93])$ from the same original RCTs adopted stratification of reporting of the results either for patients aged 55 years or older (Dols, et al.), history of treatment resistant depression [29, 30] and/or mixed features [94]. Moreover, lurasidone loose D2 postsynaptic occupancy (fast dissociation time) compared to alternative antipsychotics may represent itself a plus in the management of psychotic features associated with core mood disturbances as well [95].

Interest about lurasidone in the treatment of depression with mixed features, even when associated with sub- [94] or full-threshold bipolarity rather than major depression [96, 97], is also a matter of vivid clinical debate, although the actual differential diagnostic role of "irritability" remains an argument of debate against current DSM-5 approach [10, 84, 98].

Despite the need for the future assessment of the above specific features and/or special populations, as outlined by most of the reviewed systematic reviews and additional commentaries on the matter, overall evidence of efficacy of lurasidone as (acute antidepressant) monotherapy for adult patients with $\mathrm{BD}$ has an additional translational value [20, 21], as many individuals with BD are treated with polypharmacy even in circumstances where the most adequate initial approach would be monotherapy $[17,18]$, with potential detrimental effects on overall treatment adherence $[99,100]$.

Additional outcomes in cognitive data analyses are nonetheless awaited to determine if there is a key difference between lurasidone and other SGAs with respect to efficacy $[63,101]$, stating both the core relevance of cognitive symptoms of bipolar depression $[102,103]$ and the recommendations for future trials to account for personalized or individualized medicine (including biomarkers) even in $\mathrm{BD}$ [104].

Among others, clinical concerns raised upon overview of qualitative and quantitative evidence of lurasidone in $\mathrm{BD}$ would regard the need for inclusion of active compound alternative arms in future RCTs (e.g., fixed versus standard dose head-to-head comparisons of lurasidone against OFC, quetiapine, or alternative SGAs). Once again, long-term maintenance double-blind (extension) studies are likewise warranted [105]. Ideally, independent controlled trials would 
test whether any significant statistical and/or clinical threshold effect would be detected in RCTs directly comparing mono- versus adjunctive therapy regimens (regardless the presence of a third arm including placebo).

The need for additional information on special populations and/or clinical presentations is likewise compelling, especially considering that trials based on the Diagnostic and Statistical Manual Fifth Edition (DSM-5) [106] specifiers of mixed features or rapid-cycling specifier are missing (or yet to be disclosed to the public at writing time), as well as additional information about otherwise relevant course and specifiers not (yet?) accounted by the DSM, including, but not limited to, predominant polarity index [53], stratification of results and specific analyses about gender, and differential comorbidity profile, which may in turn play a differential impact on both efficacy and tolerability outcome measures as recently stressed out by comprehensive evidence-based guidelines for treating BD [107].

4.3. Concluding Remarks and Future Perspectives. Overall, the present overview outlined concordant unmet needs and recommendations about the use and potential future avenues of lurasidone in the treatment of bipolar depression in adults, with a special emphasis towards its therapeutic potential for cases of treatment resistant and/or mixed features of bipolar depression. In conclusion, lurasidone holds clinical potential as a novel, efficacious pharmacological treatment for bipolar depression [66]. However, the present overview confirms that current data on its use in the BD-I population are limited by publication bias and standardization of trial studies design. To this end, while its monotherapy and once a day administration coupled with relatively favorable metabolic and cognitive profile indeed represent an intriguing opportunity for policy-makers and budget holders as well the prescribing clinicians and the patients, more extensive research, both longer in duration and independently conducted, is needed.

\section{Disclosure}

Since this is a systematic review of systematic reviews, no ethical approval was needed.

\section{Conflicts of Interest}

The authors declare that there are no conflicts of interest regarding the publication of this paper. None of the authors contributing to the present work has any tie to disclose in conjunction with any drug manufacturer.

\section{References}

[1] APA, Diagnostic and Statistical Manual for Mental Disorders, APA, Washington, DC, USA, 4th edition, 1994.

[2] American Psychiatric Association, "Bipolar and related disorders," in Diagnostic and Statistical Manual for Mental Disorders, p. 123, American Psychiatric Association, Washington, DC, USA, 2013.

[3] H. A. Swartz and M. E. Thase, "Pharmacotherapy for the treatment of acute bipolar II depression: current evidence," The Journal of Clinical Psychiatry, vol. 72, no. 3, pp. 356-366, 2011.
[4] K. N. Fountoulakis, Bipolar Disorder: An Evidence-Based Guide to Manic Depression, Springer, New York, NY, USA, 2014.

[5] C. F. Baldassano, A. Hosey, and J. Coello, "Bipolar depression: an evidence-based approach," Current Psychiatry Reports, vol. 13, no. 6, pp. 483-487, 2011.

[6] J. Zohar, S. Stahl, H.-J. Moller et al., "A review of the current nomenclature for psychotropic agents and an introduction to the Neuroscience-based Nomenclature," European Neuropsychopharmacology, vol. 25, no. 12, pp. 2318-2325, 2015.

[7] B. Stubbs, D. Vancampfort, M. Solmi, N. Veronese, and M. Fornaro, "How common is bipolar disorder in general primary care attendees? A systematic review and meta-analysis investigating prevalence determined according to structured clinical assessments," Australian and New Zealand Journal of Psychiatry, vol. 50, no. 7, pp. 631-639, 2016.

[8] K. N. Fountoulakis, X. Gonda, E. Vieta, and Z. Rihmer, "Class effect of pharmacotherapy in bipolar disorder: fact or misbelief?" Annals of General Psychiatry, vol. 10, article 8, 2011.

[9] J. K. Rybakowski, "Bipolarity and inadequate response to antidepressant drugs: clinical and psychopharmacological perspective," Journal of Affective Disorders, vol. 136, no. 1-2, pp. e13e19, 2012.

[10] M. Fornaro, M. Martino, C. De Pasquale, and D. Moussaoui, "The argument of antidepressant drugs in the treatment of bipolar depression: mixed evidence or mixed states?" Expert Opinion on Pharmacotherapy, vol. 13, no. 14, pp. 2037-2051, 2012.

[11] I. Pacchiarotti, D. J. Bond, R. J. Baldessarini et al., "The International Society for Bipolar Disorders (ISBD) task force report on antidepressant use in bipolar disorders," The American Journal of Psychiatry, vol. 170, no. 11, pp. 1249-1262, 2013.

[12] M. Sagud, A. Mihaljevic-Peles, D. Begic et al., "Antipsychotics as antidepressants: what is the mechanism?" Psychiatria Danubina, vol. 23, no. 3, pp. 302-307, 2011.

[13] B. M. Wright, E. H. Eiland, and R. Lorenz, "Augmentation with atypical antipsychotics for depression: a review of evidencebased support from the medical literature," Pharmacotherapy, vol. 33, no. 3, pp. 344-359, 2013.

[14] L. Bjørklund, H. T. Horsdal, O. Mors, S. D. Østergaard, and C. Gasse, "Trends in the psychopharmacological treatment of bipolar disorder: a nationwide register-based study," Acta Neuropsychiatrica, vol. 28, no. 2, pp. 75-84, 2016.

[15] S. Dodd, B. S. Fernandes, and O. M. Dean, "Future directions for pharmacotherapies for treatment-resistant bipolar disorder," Current Neuropharmacology, vol. 13, no. 5, pp. 656-662, 2015.

[16] R. M. Post, "Treatment of bipolar depression: evolving recommendations," Psychiatric Clinics of North America, vol. 39, no. 1, pp. 11-33, 2016.

[17] M. Fornaro, D. De Berardis, A. S. Koshy et al., "Prevalence and clinical features associated with bipolar disorder polypharmacy: a systematic review," Neuropsychiatric Disease and Treatment, vol. 12, pp. 719-735, 2016.

[18] M. Fornaro, B. Stubbs, D. De Berardis et al., "Atypical antipsychotics in the treatment of acute bipolar depression with mixed features: a systematic review and exploratory meta-analysis of placebo-controlled clinical trials," International Journal of Molecular Sciences, vol. 17, no. 2, article 241, 2016.

[19] A. Shah, P. Yadav, M. Chaudhari, J. Rai, and N. Kantharia, "Bipolar disorder: a review of current U.S. Food and Drug Administration approved pharmacotherapy," International Journal of Basic and Clinical Pharmacology, pp. 623-631, 2015. 
[20] R. S. McIntyre, D. S. Cha, R. D. Kim, and R. B. Mansur, "A review of FDA-approved treatment options in bipolar depression," CNS Spectrums, vol. 18, supplement 1, pp. 4-21, 2013.

[21] R. S. McIntyre, D. S. Cha, R. D. Kim, and R. B. Mansur, "A review of FDA-approved treatment options in bipolar depression," CNS Spectrums, vol. 18, supplement 1, pp. 1-21, 2013.

[22] R. Bawa and J. R. Scarff, "Lurasidone: a new treatment option for bipolar depression-a review," Innovations in Clinical Neuroscience, vol. 12, no. 1-2, pp. 21-23, 2015.

[23] A. Loebel, J. Cucchiaro, R. Silva et al., "Lurasidone monotherapy in the treatment of bipolar I depression: a randomized, doubleblind, placebo-controlled study," American Journal of Psychiatry, vol. 171, no. 2, pp. 160-168, 2014.

[24] A. Loebel, J. Cucchiaro, R. Silva et al., "Lurasidone as adjunctive therapy with lithium or valproate for the treatment of bipolar I depression: a randomized, double-blind, placebo-controlled study," American Journal of Psychiatry, vol. 171, no. 2, pp. 169177, 2014.

[25] T. Suppes, H. Kroger, A. Pikalov, and A. Loebel, "Lurasidone adjunctive with lithium or valproate for bipolar depression: a placebo-controlled trial utilizing prospective and retrospective enrolment cohorts," Journal of Psychiatric Research, vol. 78, pp. 86-93, 2016.

[26] A. Dols, D. Rhebergen, A. Beekman, R. Kupka, M. Sajatovic, and M. L. Stek, "Psychiatric and medical comorbidities: results from a bipolar elderly cohort study," American Journal of Geriatric Psychiatry, vol. 22, no. 11, pp. 1066-1074, 2014.

[27] T. Ketter, K. Sarma, and R. Silva, "Lurasidone in bipolar I depression: a 24-week, open-label extension study [abstract no. 17 plus poster]," in Proceedings of the Annual Meeting of the American Society of Clinical Psychopharmacology, Hollywood, Fla, USA, 2014.

[28] T. A. Ketter, K. Sarma, R. Silva, H. Kroger, J. Cucchiaro, and A. Loebel, "Lurasidone in the long-term treatment of patients with bipolar disorder: a 24-week open-label extension study," Depression and Anxiety, vol. 33, no. 5, pp. 424-434, 2016.

[29] C. B. Schaffer, L. C. Schaffer, T. E. Nordahl, N. M. Stark, and C. E. Gohring, "An open trial of lurasidone as an acute and maintenance adjunctive treatment for outpatients with treatment-resistant bipolar disorder," Journal of Clinical Psychopharmacology, vol. 36, no. 1, pp. 88-89, 2016.

[30] I. R. McGrane and M. Stuhec, "Comment on an open trial of lurasidone as an acute and maintenance adjunctive treatment for outpatients with treatment-resistant bipolar disorder," Journal of Clinical Psychopharmacology, vol. 36, no. 5, pp. 520-521, 2016.

[31] L. Citrome, T. A. Ketter, J. Cucchiaro, and A. Loebel, "Clinical assessment of lurasidone benefit and risk in the treatment of bipolar I depression using number needed to treat, number needed to harm, and likelihood to be helped or harmed," Journal of Affective Disorders, vol. 155, no. 1, pp. 20-27, 2014.

[32] L. Citrome, "Number needed to treat: what it is and what it isn't, and why every clinician should know how to calculate it," Journal of Clinical Psychiatry, vol. 72, no. 3, pp. 412-413, 2011.

[33] L. Alphs, J. Berwaerts, and I. Turkoz, "Limited utility of number needed to treat and the polarity index for bipolar disorder to characterize treatment response," European Neuropsychopharmacology, vol. 23, no. 11, pp. 1597-1599, 2013.

[34] R. Ganann, D. Ciliska, and H. Thomas, "Expediting systematic reviews: methods and implications of rapid reviews," Implementation Science, vol. 5, no. 1, article 56, 2010.
[35] H. Bastian, P. Glasziou, and I. Chalmers, "Seventy-five trials and eleven systematic reviews a day: how will we ever keep up?" PLoS Medicine, vol. 7, no. 9, Article ID e1000326, 2010.

[36] D. Moher, J. Tetzlaff, A. C. Tricco, M. Sampson, and D. G. Altman, "Epidemiology and reporting characteristics of systematic reviews," PLoS Medicine, vol. 4, no. 3, article e78, 2007.

[37] T. D. Pigott, Advances in Meta-Analysis, Statistics for Social and Behavioral Sciences, Springer, New York, NY, USA, 2012.

[38] R. M. Turner, S. M. Bird, and J. P. T. Higgins, "The impact of study size on meta-analyses: examination of underpowered studies in cochrane reviews," PLoS ONE, vol. 8, no. 3, Article ID e59202, 2013.

[39] V. Smith, D. Devane, C. M. Begley, and M. Clarke, "Methodology in conducting a systematic review of systematic reviews of healthcare interventions," BMC Medical Research Methodology, vol. 11, article 15, 2011

[40] M. Tsagris and K. C. Fragkos, "Umbrella reviews, overviews of reviews, and meta-epidemiologic studies: similarities and differences," in Umbrella Reviews, pp. 43-54, Springer International Publishing, Cham, Switzerland, 2016.

[41] D. Moher, L. Shamseer, M. Clarke et al., "Preferred reporting items for systematic review and meta-analysis protocols (PRISMA-P) 2015 statement," Systematic Reviews, vol. 4, no. 1, p. 1, 2015.

[42] B. J. Shea, J. M. Grimshaw, G. A. Wells et al., "Development of AMSTAR: a measurement tool to assess the methodological quality of systematic reviews," BMC Medical Research Methodology, vol. 7, no. 1, article 10, 2007.

[43] B. J. Shea, C. Hamel, G. A. Wells et al., "AMSTAR is a reliable and valid measurement tool to assess the methodological quality of systematic reviews," Journal of Clinical Epidemiology, vol. 62, no. 10, pp. 1013-1020, 2009.

[44] J. Kung, F. Chiappelli, O. O. Cajulis et al., "From systematic reviews to clinical recommendations for evidence-based health care: validation of revised assessment of multiple systematic reviews (R-AMSTAR) for grading of clinical relevance," The Open Dentistry Journal, vol. 4, no. 1, 2010.

[45] K. Hemming, T. Pinkney, K. Futaba, M. Pennant, D. G. Morton, and R. J. Lilford, "A systematic review of systematic reviews and panoramic meta-analysis: staples versus sutures for surgical procedures," PLoS ONE, vol. 8, no. 10, Article ID e75132, 2013.

[46] M. De Hert, W. Yu, J. Detraux, K. Sweers, R. Van Winkel, and C. U. Correll, "Body weight and metabolic adverse effects of asenapine, iloperidone, lurasidone and paliperidone in the treatment of schizophrenia and bipolar disorder," CNS Drugs, vol. 26, no. 9, pp. 733-759, 2012.

[47] F. I. Tarazi and S. M. Stahl, "Iloperidone, asenapine and lurasidone: a primer on their current status," Expert Opinion on Pharmacotherapy, vol. 13, no. 13, pp. 1911-1922, 2012.

[48] K. Gao, C. Yuan, R. Wu et al., "Important clinical features of atypical antipsychotics in acute bipolar depression that inform routine clinical care: a review of pivotal studies with number needed to treat," Neuroscience Bulletin, vol. 31, no. 5, pp. 572588,2015

[49] M. Sanford and S. Dhillon, "Lurasidone: a review of its use in adult patients with bipolar I depression," CNS Drugs, vol. 29, no. 3, pp. 253-263, 2015.

[50] R. R. Jaeschke, M. Sowa-Kućma, P. Pańczyszyn-Trzewik, P. Misztak, K. Styczeń, and W. Datka, "Lurasidone: the 2016 update on the pharmacology, efficacy and safety profile," Pharmacological Reports, vol. 68, no. 4, pp. 748-755, 2016. 
[51] Y. S. Woo, H. R. Wang, and W.-M. Bahk, "Lurasidone as a potential therapy for bipolar disorder," Neuropsychiatric Disease and Treatment, vol. 9, pp. 1521-1529, 2013.

[52] L. J. Findlay, P. El-Mallakh, and R. S. El-Mallakh, "Management of bipolar I depression: clinical utility of lurasidone," Therapeutics and Clinical Risk Management, vol. 11, pp. 75-81, 2015.

[53] J. Angst, "The course of affective disorders," Archiv für Psychiatrie und Nervenkrankheiten, vol. 226, no. 1, pp. 65-73, 1978.

[54] J. P. T. Higgins, D. G. Altman, P. C. Gøtzsche et al., "The Cochrane Collaboration's tool for assessing risk of bias in randomised trials," British Medical Journal, vol. 343, no. 7829, Article ID d5928, 2011.

[55] D. Pieper, R. B. Buechter, L. Li, B. Prediger, and M. Eikermann, "Systematic review found AMSTAR, but not R(evised)AMSTAR, to have good measurement properties," Journal of Clinical Epidemiology, vol. 68, no. 5, pp. 574-583, 2015.

[56] C. M. Faggion, "Critical appraisal of AMSTAR: challenges, limitations, and potential solutions from the perspective of an assessor," BMC Medical Research Methodology, vol. 15, no. 1, article 63, 2015.

[57] I. Popovich, B. Windsor, V. Jordan, M. Showell, B. Shea, and C. M. Farquhar, "Methodological quality of systematic reviews in subfertility: a comparison of two different approaches," PLoS ONE, vol. 7, no. 12, Article ID e50403, 2012.

[58] X. Qi, M. Yang, W. Ren et al., "Find duplicates among the PubMed, EMBASE, and cochrane library databases in systematic review," PLoS ONE, vol. 8, no. 8, Article ID e71838, 2013.

[59] A. Loebel, J. Xu, J. Hsu, J. Cucchiaro, and A. Pikalov, "The development of lurasidone for bipolar depression," Annals of the New York Academy of Sciences, vol. 1358, no. 1, pp. 95-104, 2015.

[60] L. Citrome, "A review of the pharmacology, efficacy and tolerability of recently approved and upcoming oral antipsychotics: an evidence-based medicine approach," CNS Drugs, vol. 27, no. 11, pp. 879-911, 2013.

[61] K. N. Fountoulakis, M. Gazouli, J. Kelsoe, and H. Akiskal, "The pharmacodynamic properties of lurasidone and their role in its antidepressant efficacy in bipolar disorder," European Neuropsychopharmacology, vol. 25, no. 3, pp. 335-342, 2015.

[62] W. M. Greenberg and L. Citrome, "Pharmacokinetics and pharmacodynamics of lurasidone hydrochloride, a secondgeneration antipsychotic: a systematic review of the published literature," Clinical Pharmacokinetics, vol. 56, no. 5, pp. 493-503, 2017.

[63] R. S. McIntyre, D. S. Cha, M. Alsuwaidan, D. McIntosh, A. M. Powell, and J. M. Jerrell, "A review of published evidence reporting on the efficacy and pharmacology of lurasidone," Expert Opinion on Pharmacotherapy, vol. 13, no. 11, pp. 16531659, 2012.

[64] L. Orsolini, C. Tomasetti, A. Valchera et al., "An update of safety of clinically used atypical antipsychotics," Expert Opinion on Drug Safety, vol. 15, no. 10, pp. 1329-1347, 2016.

[65] J. M. Meyer, A. D. Loebel, and E. Schweizer, "Lurasidone: a new drug in development for schizophrenia," Expert Opinion on Investigational Drugs, vol. 18, no. 11, pp. 1715-1726, 2009.

[66] R. Franklin, S. Zorowitz, A. K. Corse, A. S. Widge, and T. Deckersbach, "Lurasidone for the treatment of bipolar depression: an evidence-based review," Neuropsychiatric Disease and Treatment, vol. 11, pp. 2143-2152, 2015.

[67] K. Rajagopalan, E. D. Bacci, K. W. Wyrwich, A. Pikalov, and A. Loebel, "The direct and indirect effects of lurasidone monotherapy on functional improvement among patients with bipolar depression: results from a randomized placebo-controlled trial," International Journal of Bipolar Disorders, vol. 4, no. 1, p. 1, 2016.

[68] Y.-Y. Chiu, L. Ereshefsky, S. H. Preskorn, N. Poola, and A. Loebel, "Lurasidone drug-drug interaction studies: a comprehensive review," Drug Metabolism and Drug Interactions, vol. 29, no. 3, pp. 191-202, 2014.

[69] W. K. Kennedy, M. W. Jann, and E. C. Kutscher, "Clinically significant drug interactions with atypical antipsychotics," CNS Drugs, vol. 27, no. 12, pp. 1021-1048, 2013.

[70] J. De Leon, V. Santoro, C. D’Arrigo, and E. Spina, "Interactions between antiepileptics and second-generation antipsychotics," Expert Opinion on Drug Metabolism and Toxicology, vol. 8, no. 3, pp. 311-334, 2012.

[71] L. Fala, "Latuda (Lurasidone $\mathrm{HCl}$ ) Receives 2 New Indications for Use in Bipolar Depression as Monotherapy and as Adjunctive Therapy with Lithium or Valproate," American Health \& Drug Benefits.

[72] “Sunivon ${ }^{\circledR}$. Latuda ${ }^{\circledR}$ (lurasidone $\mathrm{HCl}$ ) Prescribing Information," 2016, https://www.google.it $/ \mathrm{url}$ ? sa $=\mathrm{t} \& \mathrm{rct}=\mathrm{j} \& \mathrm{q}=\& \mathrm{esrc}=\mathrm{s} \&$ source $=$ web $\& \mathrm{~cd}=1 \& \mathrm{cad}=\mathrm{rja} \& \mathrm{uact}=8 \& \mathrm{ved}=0$ ahUKEwjc $4 \mathrm{oCE}-$ 3e7PAhVGshQKHXiQBwQQFggoMAA\&url=http\%3A\%2F\% 2Fwww.latuda.com\%2FLatudaPrescribingInformation.pdf\& usg=AFQjCNH01TNyYsBUFNHXmkeYUltV0h9_mA.

[73] A. Loebel and L. Citrome, "Lurasidone: a novel antipsychotic agent for the treatment of schizophrenia and bipolar depression," Psychiatrist, vol. 39, no. 5, pp. 237-241, 2015.

[74] T. Horisawa, T. Ishibashi, H. Nishikawa et al., "The effects of selective antagonists of serotonin 5-HT7 and 5-HT1A receptors on MK-801-induced impairment of learning and memory in the passive avoidance and Morris water maze tests in rats: mechanistic implications for the beneficial effects of the novel atypical antipsychotic lurasidone," Behavioural Brain Research, vol. 220, no. 1, pp. 83-90, 2011.

[75] T. Ishibashi, T. Horisawa, K. Tokuda et al., "Pharmacological profile of lurasidone, a novel antipsychotic agent with potent 5hydroxytryptamine 7 (5-HT7) and 5-HT1A receptor activity," Journal of Pharmacology and Experimental Therapeutics, vol. 334 , no. 1, pp. 171-181, 2010.

[76] K. N. Fountoulakis, J. R. Kelsoe, and H. Akiskal, "Receptor targets for antidepressant therapy in bipolar disorder: an overview," Journal of Affective Disorders, vol. 138, no. 3, pp. 222238, 2012.

[77] J. K. Zubieta and N. E. Alessi, "Is there a role of serotonin in the disruptive behavior disorders? A literature review," Journal of Child and Adolescent Psychopharmacology, vol. 3, no. 1, pp. 11-35, 1993.

[78] L. N. Yatham, J. M. Goldstein, E. Vieta et al., "Atypical antipsychotics in bipolar depression: potential mechanisms of action," Journal of Clinical Psychiatry, vol. 66, supplement 5, pp. 40-48, 2005.

[79] P. Blier and N. M. Ward, "Is there a role for 5- $\mathrm{HT}_{1 \mathrm{~A}}$ agonists in the treatment of depression?" Biological Psychiatry, vol. 53, no. 3, pp. 193-203, 2003.

[80] E. Brugue and E. Vieta, "Atypical antipsychotics in bipolar depression: neurobiological basis and clinical implications," Progress in Neuro-Psychopharmacology and Biological Psychiatry, vol. 31, no. 1, pp. 275-282, 2007.

[81] L. N. Cates, A. J. Roberts, S. Huitron-Resendiz, and P. B. Hedlund, "Effects of lurasidone in behavioral models of depression. Role of the 5-HT7 receptor subtype," Neuropharmacology, vol. 70, pp. 211-217, 2013. 
[82] M. Huang, M. Horiguchi, A. R. Felix, and H. Y. Meltzer, "5HT1A and 5-HT7 receptors contribute to lurasidone-induced dopamine efflux," NeuroReport, vol. 23, no. 7, pp. 436-440, 2012.

[83] O. Mnie-Filali, L. Lambas-Señas, H. Scarna, and N. Haddjeri, "Therapeutic potential of 5-HT7 receptors in mood disorders," Current Drug Targets, vol. 10, no. 11, pp. 1109-1117, 2009.

[84] H. Y. Meltzer, "The role of serotonin in antipsychotic drug action," Neuropsychopharmacology, vol. 21, no. 2, pp. 106S-115S, 1999.

[85] R. J. Roberts, K. K. Lohano, and R. S. El-Mallakh, "Antipsychotics as antidepressants," Asia-Pacific Psychiatry, vol. 8, no. 3, pp. 179-188, 2015.

[86] D. K. Shayegan and S. M. Stahl, "Atypical antipsychotics: matching receptor profile to individual patient's clinical profile," CNS Spectrums, vol. 9, no. 10, pp. 6-14, 2004.

[87] N. A. Keks, J. Hope, and D. Castle, "Lurasidone: an antipsychotic with antidepressant effects in bipolar depression?" Australasian Psychiatry, vol. 24, no. 3, pp. 289-291, 2016.

[88] F. Fang, H. Sun, Z. Wang, M. Ren, J. R. Calabrese, and K. Gao, "Antipsychotic drug-induced somnolence: incidence, mechanisms, and management," CNS Drugs, vol. 30, no. 9, pp. 845-867, 2016.

[89] J. De Fruyt, E. Deschepper, K. Audenaert et al., "Second generation antipsychotics in the treatment of bipolar depression: a systematic review and meta-analysis," Journal of Psychopharmacology, vol. 26, no. 5, pp. 603-617, 2012.

[90] L. Citrome, A. Pikalov, M. Tocco et al., Sunovion Pharmaceuticals Europe Ltd. to Present New Data on LATUDA ${ }^{\circledR}$ ? (lurasidone) at the 23rd European Congress of Psychiatry.

[91] M. Sajatovic, D. Ng-Mak, C. T. Solem, F. Lin, K. Rajagopalan, and A. Loebel, "Dosing patterns and medication adherence in bipolar disorder patients treated with lurasidone: a US retrospective claims database analysis," Therapeutic Advances in Psychopharmacology, vol. 6, no. 6, pp. 355-368, 2016.

[92] M. G. Carta, M. F. Moro, A. E. Nardi, and J. R. Calabrese, "Potential use of lurasidone for the treatment of bipolar psychosis," Expert Opinion on Investigational Drugs, vol. 24, no. 4, pp. 575584, 2015.

[93] A. Loebel, C. Siu, K. Rajagopalan, A. Pikalov, J. Cucchiaro, and T. A. Ketter, "Recovery in bipolar depression: post-hoc analysis of a placebo-controlled lurasidone trial followed by a long-term continuation study," Journal of Affective Disorders, vol. 186, pp. 376-382, 2015.

[94] R. S. McIntyre, J. Cucchiaro, A. Pikalov, H. Kroger, and A. Loebel, "Lurasidone in the treatment of bipolar depression with mixed (subsyndromal hypomanic) features: post hoc analysis of a randomized placebo-controlled trial," The Journal of Clinical Psychiatry, vol. 76, no. 4, pp. 398-405, 2015.

[95] J. Lataster, J. Van Os, L. De Haan et al., "Emotional experience and estimates of D2 receptor occupancy in psychotic patients treated with haloperidol, risperidone, or olanzapine: an experience sampling study," Journal of Clinical Psychiatry, vol. 72, no. 10, pp. 1397-1404, 2011.

[96] A. Nierenberg, J. Tsai, Y. Mao, A. Pikalov, T. Suppes, and A. Loebel, "Efficacy of lurasidone in major depression with mixed features: pattern of improvement in depressive and manic symptoms," European Psychiatry, vol. 33, p. S423, 2016.

[97] T. Suppes, R. Silva, J. Cucchiaro et al., "Lurasidone for the treatment of major depressive disorder with mixed features: a randomized, double-blind, placebo-controlled study," American Journal of Psychiatry, vol. 173, no. 4, pp. 400-407, 2016.
[98] J. Hu, R. Mansur, and R. S. McIntyre, "Mixed specifier for bipolar mania and depression: highlights of DSM-5 changes and implications for diagnosis and treatment in primary care," The Primary Care Companion for CNS Disorders, vol. 16, no. 2, 2014.

[99] M. Fornaro, D. De Berardis, F. Iasevoli et al., "Corrigendum to 'Treatment adherence towards prescribed medications in bipolar-II acute depressed patients: Relationship with cyclothymic temperament and "therapeutic sensation seeking" in response towards subjective intolerance to pain' [J. Affect. Disord. 151 (2) (November 2013), 596-604]," Journal of Affective Disorders, vol. 170, p. 22, 2015.

[100] M. Fornaro, D. De Berardis, F. Iasevoli et al., "Treatment adherence towards prescribed medications in bipolar-II acute depressed patients: relationship with cyclothymic temperament and 'therapeutic sensation seeking' in response towards subjective intolerance to pain," Journal of Affective Disorders, vol. 151, no. 2, pp. 596-604, 2013.

[101] L. N. Yatham, S. Mackala, J. Basivireddy et al., "Lurasidone versus treatment as usual for cognitive impairment in euthymic patients with bipolar I disorder: a randomised, open-label, pilot study," The Lancet Psychiatry, vol. 4, no. 3, pp. 208-217, 2017.

[102] K. E. Burdick, T. A. Ketter, J. F. Goldberg, and J. R. Calabrese, "Assessing cognitive function in bipolar disorder: challenges and recommendations for clinical trial design," Journal of Clinical Psychiatry, vol. 76, no. 3, pp. e342-e350, 2015.

[103] C. T. Sudhir Kumar and S. Frangou, "Clinical implications of cognitive function in bipolar disorder," Therapeutic Advances in Chronic Disease, vol. 1, no. 3, pp. 85-93, 2010.

[104] M. A. Frye, M. L. Prieto, W. V. Bobo et al., "Current landscape, unmet needs, and future directions for treatment of bipolar depression," Journal of Affective Disorders, vol. 169, no. 1, pp. S17S23, 2014.

[105] A. Pikalov, J. Tsai, Y. Mao, R. Silva, J. Cucchiaro, and A. Loebel, "Long-term use of lurasidone in patients with bipolar disorder: safety and effectiveness over 2 years of treatment," International Journal of Bipolar Disorders, vol. 5, no. 1, article 9, 2017.

[106] American Psychiatric Association Publishing, Diagnostic and Statistical Manual of Mental Disorders (DSM-5 $\left.{ }^{\circledR}\right)$, American Psychiatric Association Publishing, 2013.

[107] G. M. Goodwin, P. M. Haddad, I. N. Ferrier et al., "Evidencebased guidelines for treating bipolar disorder: revised third edition recommendations from the British Association for Psychopharmacology," Journal of Psychopharmacology, vol. 30, no. 6, pp. 495-553, 2016. 

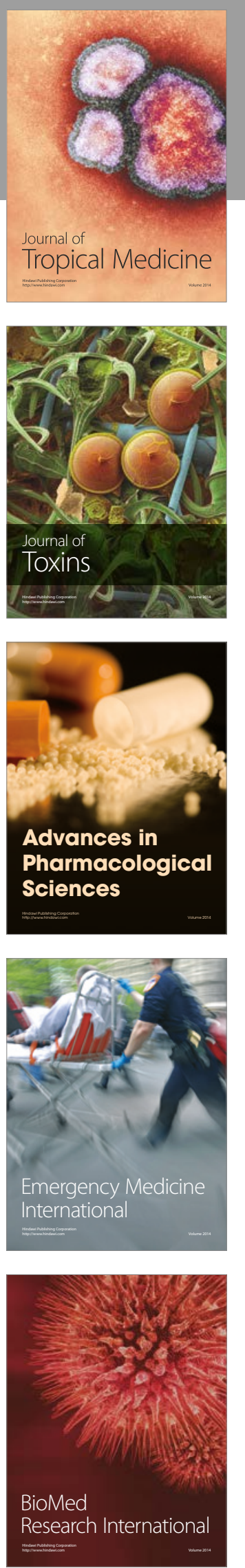
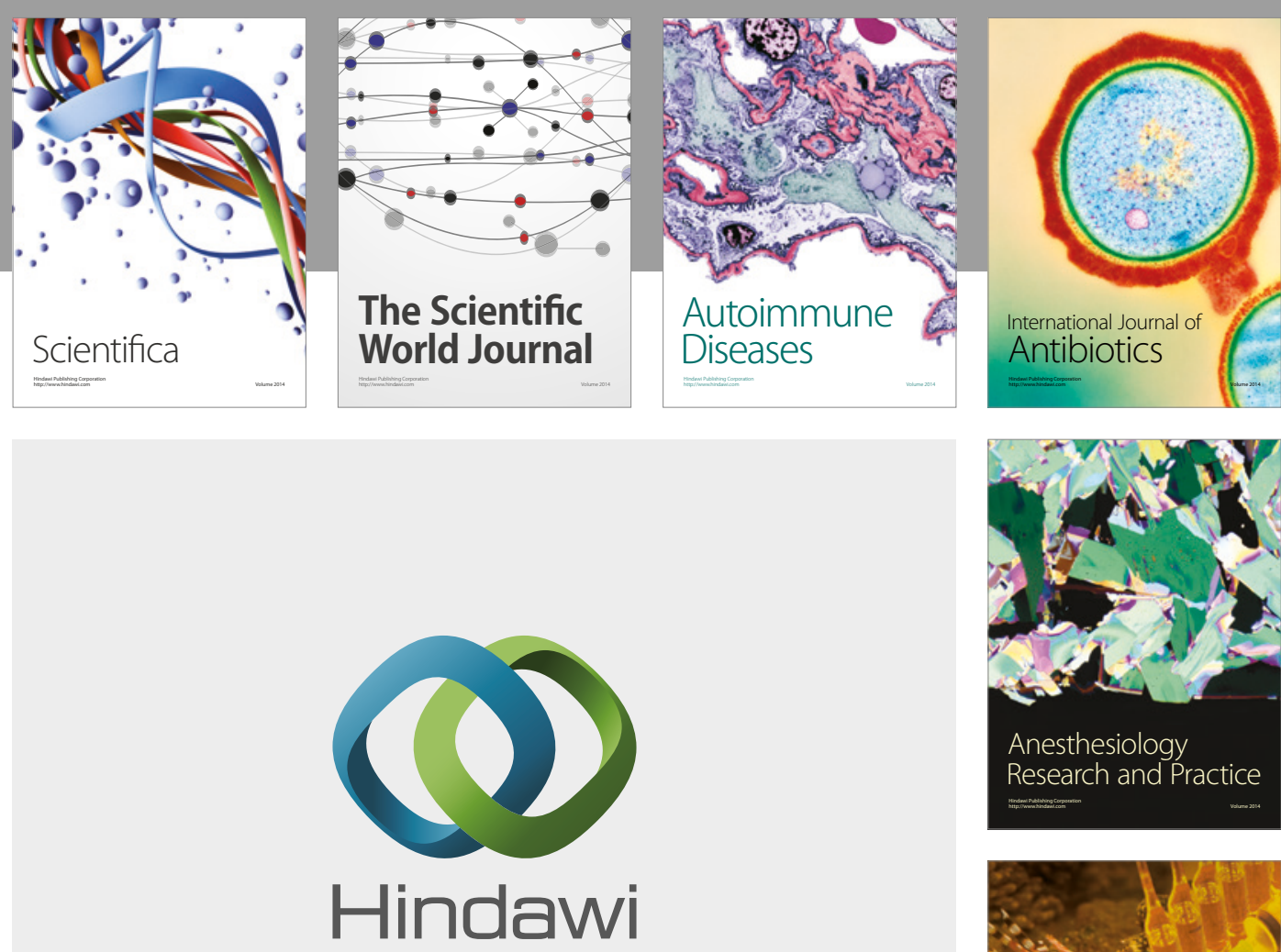

Submit your manuscripts at

https://www.hindawi.com
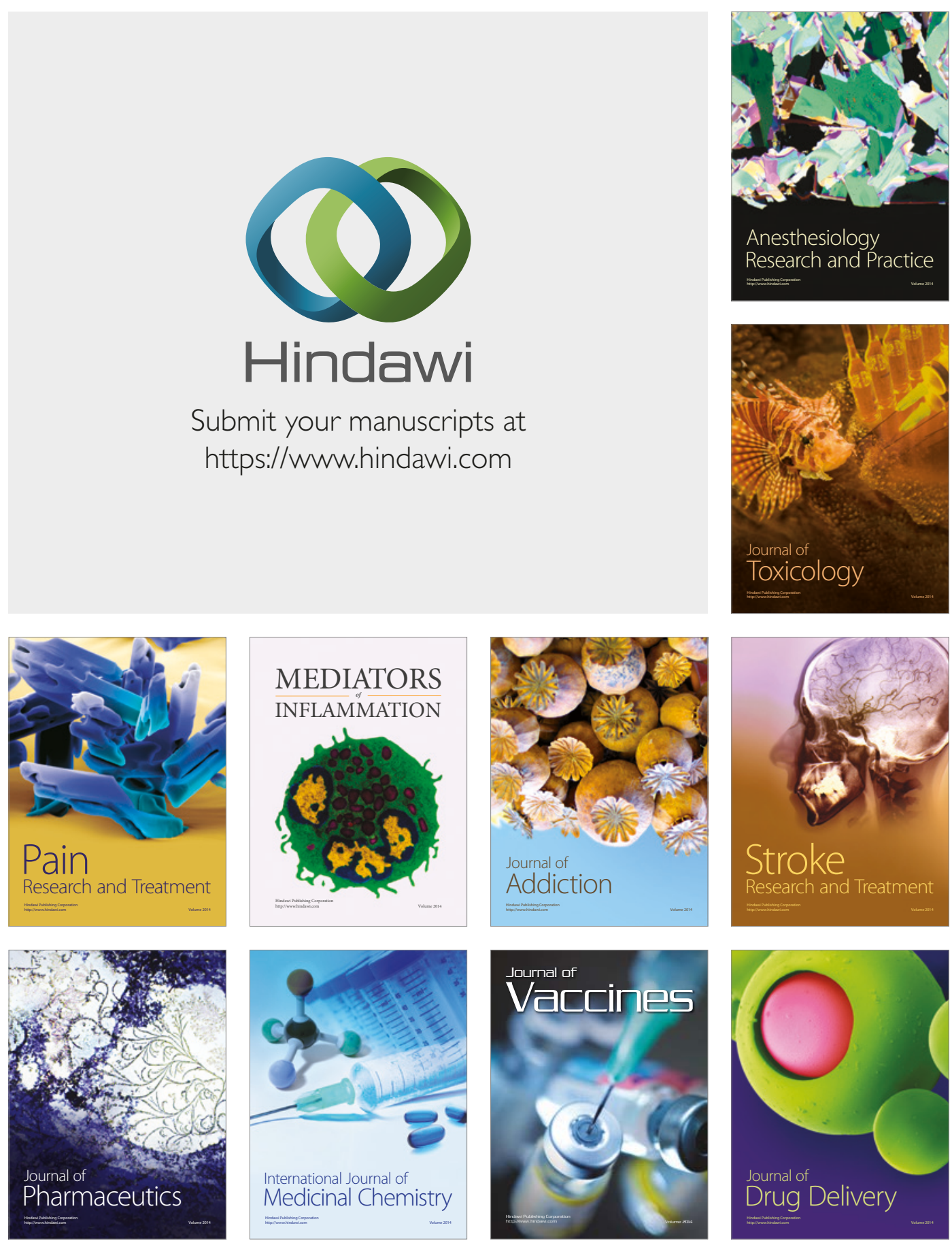